\title{
Reduction of Isolated Zygomatic Arch Fractures with Gillies Approach
}

\author{
Dong Keun Shin, Young Su Kim, Woo Sub Shim, and Hahn Jin Jung \\ Department of Otorhinolaryngology-Head and Neck Surgery, Chungbuk National University Hospital, \\ Chungbuk National University College of Medicine, Cheongju, Korea
}

\author{
길리씨 접근법을 통한 협골궁 골절의 정복 \\ 신동근 · 김영수 · 심우섭 · 정한진 \\ 충북대학교 의과대학 충북대학교병원 이비인후과학교실
}

\author{
Received December 27, 2017 \\ Revised April 9,2018 \\ Accepted April 16, 2018 \\ Address for correspondence \\ Hahn Jin Jung, MD \\ Department of Otorhinolaryngology- \\ Head and Neck Surgery, \\ Chungbuk National University \\ Hospital, Chungbuk National \\ University College of Medicine, \\ 776 1sunhwan-ro, Soewon-gu, \\ Cheongju 28644, Korea \\ Tel $+82-43-269-6157$ \\ Fax +82-43-265-6157
}

E-mail hahnjin2@naver.com
Background and Objectives The incidence of facial bone fracture is increasing. The zygomatic bone, due to its anatomical prominence, is the second most common site of all facial bone fractures. In this study, we present the clinical experiences of zygomatic arch fracture in a tertiary hospital and introduce the Gillies approach for reduction and its outcome results. Subjects and Method We collected data from retrospective chart reviews of patients who underwent surgeries from 2010 to 2017 for zygomatic arch fractures at Chungbuk National University Hospital. Data were analyzed according to age, gender, cause of trauma, location of trauma, and clinical symptoms including trismus. All surgery was performed under general anesthesia and via the use of Gillies approach. The result of surgery was evaluated by postoperative facial computed tomography.

Results Sixteen patients underwent surgery for zygomatic arch fracture. The patients had the average age of 41.3 years, a male predominance of $15: 1$ and physical assault as the most common cause of trauma. The time lag between injury and surgical reduction was 5.5 days. The surgical outcomes were assessed 'good' in 14 cases and 'moderate' in one case. Patients who had trismus preoperatively were resolved of it in all cases after operation. Postoperative complications were absent.

Conclusion The Gillies approach proved to be a relatively easy, safe, and reliable method, and its surgical outcomes was satisfactory in our experiences.

Korean J Otorhinolaryngol-Head Neck Surg 2018;61(11):588-92

Key Words Facial bone fracture · Gillies approach · Maxillofacial trauma · Zygomatic arch fracture.

\section{서 론}

협골은 미용적으로 안면의 전체적인 윤곽 및 돌출 정도, 대칭성을 결정하며, 기능적으로 저작하는 데 중요한 역할을 한다. 현대 사회에서 폭행, 교통사고, 스포츠 활동 등으로 안

This is an Open Access article distributed under the terms of the Creative Commons Attribution Non-Commercial License (https://creativecommons.org/licenses/by-nc/4.0) which permits unrestricted non-commercial use, distribution, and reproduction in any medium, provided the original work is properly cited.
면골 골절의 빈도가 증가하고 있고 특히 협골은 안면부에서 현저히 돌출되어 있기 때문에 협골 골절은 안면골 골절 중 비골 골절 다음으로 흔하다. ${ }^{1,2)}$ 협골 골절에서 적절한 수술법 을 선택하여 안면부의 만족할 만한 미용적, 기능적 회복을 하는 것은 중요하다.

협골 골절의 치료에 있어서 수술 시기 및 정복 방법에 대한 여러 보고가 있다. 저자는 협골 골절 중 협골궁 골절 환자 치 료에 있어서 비교적 간단하고 최소 침습적인 Gillies 접근법 
을 통한 비관혈적 정복술로 만족스러운 결과를 얻었기에, 골 절 원인, 수술 방법 및 술 후 결과에 대해 임상적으로 분석 보고하고, Gillies 접근법에 대해 소개하고자 한다.

\section{대상 및 방법}

2010년 4월부터 2017년 8월까지 본원 이비인후과에 내원하 여 협골궁 골절로 진단받고 Gillies 접근법을 통하여 정복술 을 시행 받은 16 명의 환자를 대상으로 하였다. 환자의 의무기 록과 영상학적 검사를 검토하여 성별, 나이, 수상 원인 및 부 위, 동반 손상, 손상 당시 개구 장애 및 기타 동반 증상을 후 향적으로 분석하였다. 수술까지의 시간, 수술 시간, 수술 후의 비대칭 정도 및 정복 성공 여부, 개구 장애 등의 증상 호전, 안 면 마비 발생 여부 등 수술 결과에 대해서도 조사하였다. 개 구 장애는 환자의 3 지폭을 기준으로 그 이하인 경우 개구 장 애가 있는 것으로 간주하였다. ${ }^{3)}$ 본 연구는 본원의 임상시험윤 리위원회(Institutional Review Board, IRB No. 2018-01-002) 심의를 승인받았다.

수술은 모두 전신마취하에 시행되었고, Gilles 접근법을 통하여 측두부 모발선에서 2 3 cm 상방에 $1 \mathrm{~cm}$ 길이의 절개 를 가한 후 심층 측두근 막과 측두근 사이로 박리하여 피부 및 심층 측두근 막을 거상한 후 협골궁 아래로 Boies 기자 등 을 삽입하여 정복하였다. 이때 안면 신경은 함께 거상되어 손 상을 피하게 된다(Fig. 1). 필요한 경우 정복 성공 여부를 확 인하기 위해 수술방에서 이동식 협골 단순 방사선 촬영을 시 행하여 평가하였다. 내부 고정은 하지 않았고, 열가소성 부목

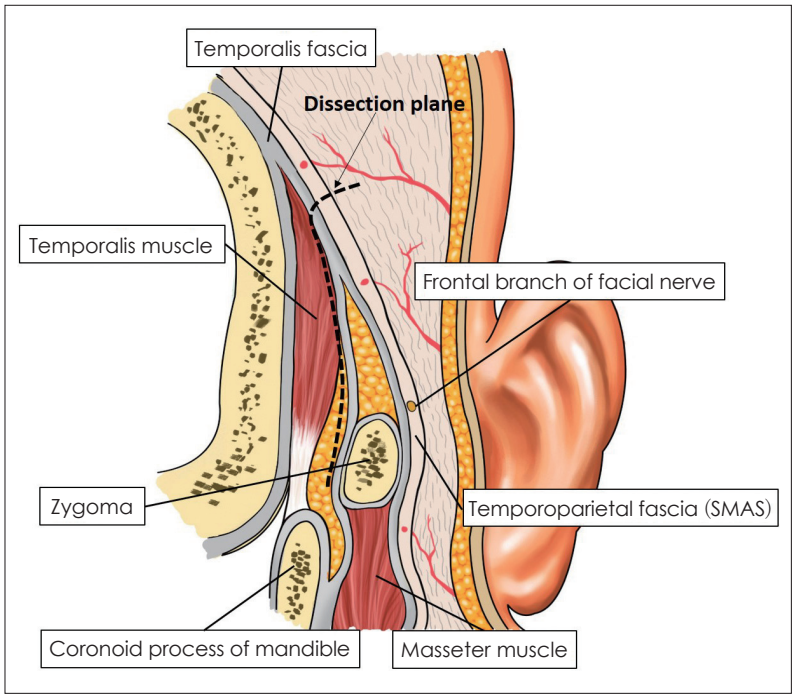

Fig. 1. Schematic drawing of zygomatic arch area. Facial nerve injury can be avoided with Gillies approach which dissection plane (black dotted line) between temporalis fascia and temporalis muscles. SMAS: superficial muscular aponeurotic system. (aqua plastic splint)을 이용하여 외부에 부목을 1주일간 유 지하였다.

수술 후의 결과는 환자의 수술 후 외관과 수술 직후 촬영 한 안면 전산화단층촬영 결과를 통해 정복된 골절편이 매우 잘 맞은 경우를 good, 약간의 전위가 있는 경우 moderate, 그 리고 정복이 잘 되지 않은 경우 poor로 평가하였다.

\section{결 과}

총 16 명 중 남자 15 명, 여자 1 명으로, 남자가 많았다. 연령대 별로 10대 1명, 20대 4명, 30대 3명, 40대 3명, 50대 1명, 60대 4명으로, 평균 연령은 41.3세였다. 수상 부위는 좌측 13 명, 우 측 3명으로 좌측이 많았다. 수상 원인은 폭행 6명, 낙상 사고 4 명, 교통사고 4명이었고 스포츠 활동으로 인한 손상 1명, 기 타 1명이 있었다(Fig. 2). 16명 모두 안면부의 변형을 주 증상 으로 호소하였으며, 수상 당시 및 수술 일자에 6명에서 개구 장애가 있었다. 동반 손상으로는 12 명에서 뇌진탕, 뇌출혈, 두개골 골절 등의 두부 손상이 있었으며, 시각 이상이나 안구 운동 장애, 안구 함몰 등의 증상은 없었다(Table 1).

수상 후 수술 일까지 경과 시간은 최저 1 일에서 10 일이었 고, 평균 5.5일이었다. 전신마취 시간은 평균 41.2분이었고 모 든 수술이 1시간을 넘기지 않았다.

수술 후 안면 비대칭에 대한 평가는 16명 중 14명은 good 이었고 1 명은 moderate, 1 명은 poor였다. 개구 장애가 있었던 6예 모두에서 수술 후 호전이 되었으며, 안면 마비가 발생한 경우는 없었다. 수술 후 감염이나 통증과 같은 합병증을 보 인 경우는 없었으며, 재수술을 시행한 경우도 없었다(Fig. 3).

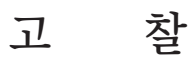

협골은 안와의 외벽 및 하벽의 일부를 이루며, 위로 전두

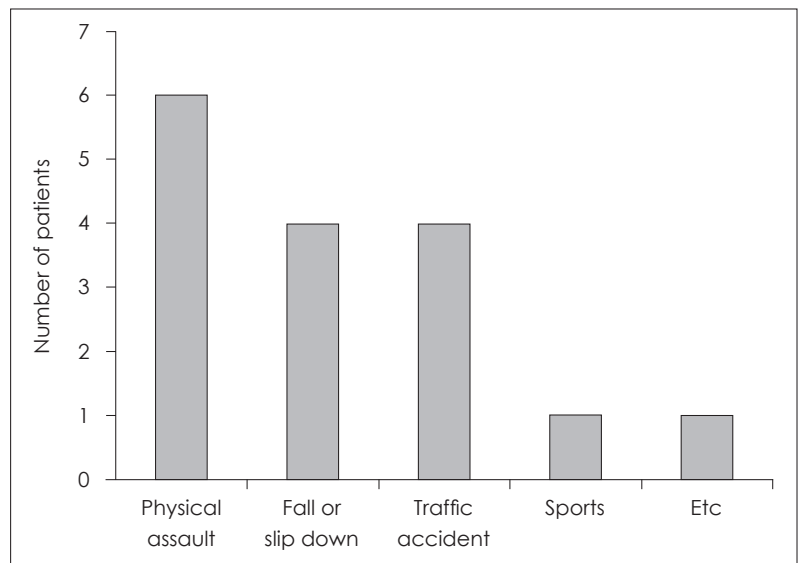

Fig. 2. Cause of injury. 
골, 외측으로 측두골, 내측으로 상악골과 결합되어 있다. 안 면부의 비골과 하악골처럼 돌출되어 있어 외상을 받기 쉬우 므로 안면골 골절에서 비골 골절과 함께 대부분을 차지하고 있다. ${ }^{2}$ 협골 골절 시 안와를 침범하여 안운동의 장애, 복시
및 안기능 자체의 문제를 야기할 수 있으며, 측두근을 압박 하거나 하악골의 구상돌기를 침범하여 개구 장애 및 동통을 유발하기도 한다. ${ }^{4}$ 또한 협골궁은 안면부의 윤곽을 이루는 주된 구조로 적절한 치료가 없을 시 안면부의 비대칭적 변형

Table 1. Characteristics of patients

\begin{tabular}{cccllcc}
\hline No. & Age & Sex & Side & Cause of Injury & Interval (days) & Results \\
\hline 1 & 68 & M & Left & Traffic accident & 7 & 2 \\
2 & 19 & F & Left & Traffic accident & 2 & Gooderate \\
3 & 38 & M & Left & Slip down & 10 & Good \\
4 & 25 & M & Left & Physical assault & 1 & Good \\
5 & 43 & M & Left & Slip down & 2 & Good \\
6 & 68 & M & Left & Slip down & 7 & Good \\
7 & 23 & M & Left & Traffic accident & 6 & Good \\
8 & 40 & M & Left & Physical assault & 8 & Good \\
9 & 33 & M & Left & Physical assault & 9 & Good \\
10 & 25 & M & Left & Physical assault & 9 & Good \\
11 & 63 & M & Left & Traffic accident & 1 & Good \\
12 & 36 & M & Right & Sports activity & 7 & Good \\
13 & 62 & $M$ & Right & Physical assault & 5 & Good \\
14 & 20 & M & Right & Etc. & 6 & Good \\
15 & 40 & $M$ & Left & Physical assault & 6 & Poor \\
16 & 58 & $M$ & Left & Slip down & Good \\
\hline
\end{tabular}
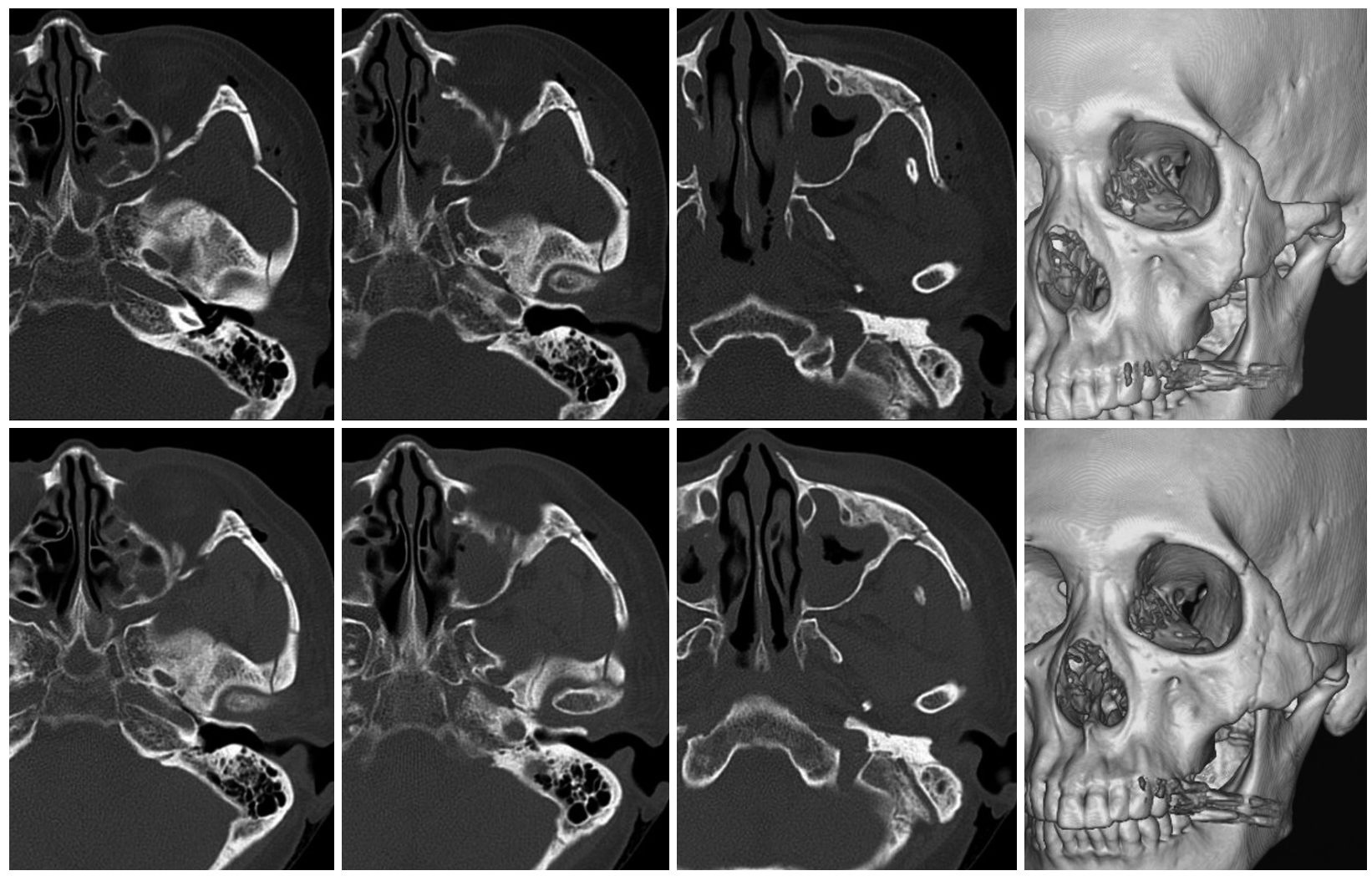

Fig. 3. Representative case. Upper line: preoperative findings. Axial CT and 3D-reconstructed CT image demonstrates the depressed left zygomatic arch fracture. Lower line: postoperative findings. Axial CT and 3D-reconstructed CT image demonstrates the stabilization of bony fragment and good alignment of zygomatic arch after reduction with Gillies approach. 3D: three dimensional, CT: computed tomography. 
이 생길 수 있으므로 적절한 진단과 치료가 중요하다. ${ }^{5)}$

협골 골절은 여러 분류 방법이 있으나, 주로 전산화단층촬 영 검사 결과에 따라 Zingg 등희의 분류에 따라 분류한다. 협 골궁 골절은 Type A1형에 해당하며, 이 밖에 안와 외연 골절 은 A2형, 안와 하연 골절은 A3형으로 분류하였고, 협골 전위 가 일어난 단골편 협골 골절(tetrapod fracture)은 B형, 다골 편 골절은 $\mathrm{C}$ 형으로 분류한다. 본 연구에서 분석한 Type $\mathrm{A} 1$, 협골궁 골절은 전체 협골 골절의 약 10 20\%를 차지한다고 알려져 있으며, ${ }^{7-10)} \mathrm{Kim}$ 등 $^{4}$ 의 연구에서는 협골궁 골절이 전 체 분류 중 $20 \%$ 를 차지하여 Type B인 삼각골절 $53 \%$ 에 이어 2 번째로 흔하였으며, Moon 등 ${ }^{11)}$ 의 연구에서는 협골 골절 중 협골궁 골절이 $31.4 \%$ 로 가장 많았다.

골절의 원인으로는 폭행이 16 명 중 6 명으로 가장 많았으며, 안와 골절에서 좌측의 골절이 더 많듯이 협골궁 골절에서도 좌측이 13예로 더 많았다. 이전 보고에서는 교통사고가 $80 \%$ 이상의 높은 빈도를 보인 바 있으나, ${ }^{12)}$ 교통사고 시에는 Type $\mathrm{B}$ 나 Type C 등 좀 더 골절 범위가 커지게 되어 협골궁 골절 에 제한을 둔 본 연구의 경우에는 폭행이 가장 많은 원인이었 다고 생각된다. 성별로는 주로 남자에서 여자에 비해 4배에서 5 배 정도 많다는 보고 ${ }^{11}$ 가 있으며 본 연구에서도 일치하였다.

협골궁 골절의 증상으로는 안면 협부의 편평화로 인한 안 면부의 비대칭적인 변형 및 개구 장애 등이 발생할 수 있다. ${ }^{13,14)}$ 개구 장애는 전위되어 함몰된 골절편에 의해 하악골의 근돌 기가 간섭이 일어나 유발된다. 본 연구에서는 수술 전 전례에 서 안면 비대칭이 있었으며, 6예에서 개구 장애가 있었다. 진 단은 병력, 증상과 함께 이학적 검사 및 방사선학적 검사로 할 수 있으며, 전산화단층촬영으로 골절 부위 및 골절편의 전 이 방향, 동반골절 등을 정확히 파악할 수 있어 진단적 가치 가 가장 높다. ${ }^{15)}$

정복수술 시기는 뇌출혈 등 다른 치명적 동반 손상을 확실 히 확인 후 시행되어야 하고 되도록 2 3주 안에는 시행해야 하며, 3주가 지나면 정복술은 불가능 하다. ${ }^{2,16,17)}$ 본 연구에서 는 수상 후 평균 5.5일에 정복술을 시행하였다. 동반 두부 손 상으로 인한 1 명에서 최장 10 일째에 수술을 시행하였으며, 정 복하는 데 있어서 특별한 어려움은 없었다.

1927년 소개된 Gillies 접근법,18,19)은 협골궁 골절에서 선 택할 수 있는 가장 간편한 비관혈적 정복술이다. 이밖에도 관 혈적 정복술을 시행하거나, 치은협 절개 등을 통해 접근할 수 있으나 수술 시간 및 절개 정도, 그리고 수술 후 결과 등을 고려하였을 때 저자들은 Gillies 접근법을 선호하고 있다. 반 흔이 남는 것에 대해 거부감이 있는 일부 환자들에 대해서는 치은협 절개를 통해 수술을 시행하고 있다. 치은협 절개의 경 우에는 피부 절개를 피할 수 있어 반흔을 남기지 않고 정복
이 가능하다는 장점이 있으나 구강 내 정상 세균총의 측두와 로의 전파로 세균 감염의 위험성이 있다는 단점이 있다. ${ }^{20)}$ 본 연구 기간 동안 2 예에서는 치은협 절개를 사용하여 정복을 시행하였다. 골절 부위 및 전위 정도에 따라 접근 방법의 결정 이 이루어져야겠으나, 협골궁 단독 골절의 경우에는 Gillies 접근법이 가장 효율적이라고 생각된다. Gillies 접근법은 안 면 신경을 포함하여 플랩을 거상 하기 때문에, 안면 신경의 마 비 증상이 오지 않는다는 장점이 핵심적이다. ${ }^{21)}$ 큰 절개선을 넣고 직접 관찰하면서 정복 정도를 평가하기에는 안면 신경의 손상 가능성이 있으며, ${ }^{22)}$ 해부학적 연구에서는 전두근으로 향하는 측두분지와 안윤근으로 향하는 협골분지가 협골 골 절 수술 시 손상될 위험이 높다고 보고된 바 있다. ${ }^{23)}$ Gillies 접근법을 선택하였을 때의 가능한 문제점은 정복이 만족스 럽게 되었는지 확인이 불가하다는 점일 것이다. 이를 위해 수 술장에서 영상 검사(단순 방사선 촬영, 전산화단층촬영, 초 음파, 22,24) 또는 $\left(-\mathrm{arm}^{25)}\right.$ 를 확인하여 정복 결과를 점검한다 는 보고도 있고, 최근에는 네비게이션을 사용하여 정복을 시 행한 연구 ${ }^{26)}$ 도 있다. 본 연구에서는 2 예에서 이동식 협골 단 순 방사선촬영을 시행하였으며, 1 예의 경우 poor한 결과를 보 여 재정복을 하였으며 최종적으로 moderate한 정복 정도를 보였다(No. 1 환자). 하지만 수술자의 정복되는 순간의 주관 적인 감각과 바깥에서의 촉진만으로 충분히 만족스러운 결과 를 보장할 수 있다고 생각되며, 본 연구에서도 14예 중 13예에 서 moderate 이상의 만족스러운 결과가 있었다.

Gillies 접근법을 통해 단순 정복술을 시행한 경우 골절편 의 유지가 불안정하고, 충격에 대해 보호할 장치가 없기에 골 전편을 내부에서 고정하거나 외부에서 고정 혹은 보호하는 여러 방법들이 소개되어 있다. 종이컵이나 알루미늄 수지 부 목을 사용하여 외부에서 보호하는 방법, Gillies 절개 부위를 통해 도뇨관을 삽입 팽창하거나, ${ }^{27)}$ 설압자나 열가소성 부목 (aqua plastic splint)을 이용하여 부목을 대고 봉합하는 방 법 등이 보고된바 있으며, ${ }^{28)}$ 저자들은 특별한 내부 고정 없이 열가소성 부목을 골절 부위를 포함하여 외부에 넓게 1주일 가량 거치시는 것만으로도 재전위 되거나 하는 예는 없었다. 이전의 보고에서도 협골궁의 정복이 적절하고, 골막이 손상 되지 않고 남아있다면 내부 고정 없이도 정복된 상태를 유지 할 수 있다고 한 바 있다. ${ }^{26)}$

결론적으로, 본 교실에서는 협골궁 골절의 치료로 Gillies 접근법을 통해 비교적 쉽고 빠르게 정복할 수 있었으며, 다른 접근법에 비해 안면 신경 손상 등의 부담 없이 만족스러운 정복 결과를 얻을 수 있는 방법이라고 생각된다. 


\section{REFERENCES}

1) Stack BC, Ruggiero FP. Maxillary and periorbital fractures. In: Bailey BJ, Johnson JT, Newlands SD, editors. Head and Neck Surgery-Otolaryngology. 4th ed. Philadelphia: Lippincott Williams \& Wilkins;2006. p.975-94.

2) Kim CH, Kim H, Kil DS, Yang HS, Yoon DB. [A statistical study of fractures of the facial bone]. Korean J Otorhinolaryngol-Head Neck Surg 1987;30(1):105-12.

3) Lee CH, Chang HK, Song IS. [Operative results in orbital floor fracture associated with malar tripod fracture]. J Korean Ophthalmol Soc 1999;40(7):1739-45.

4) Kim JG, We JW, Kwon JH, Cho JH. [Classification and clinical analysis of zygomatic fractures]. Korean J Otorhinolaryngol-Head Neck Surg 2008;51(4):326-30.

5) Werner JA, Frenkler JE, Lippert BM, Folz BJ. Isolated zygomatic arch fracture: report on a modified surgical technique. Plast Reconstr Surg 2002;109(3):1085-9.

6) Zingg M, Laedrach K, Chen J, Chowdhury K, Vuillemin T, Sutter F, et al. Classification and treatment of zygomatic fractures: a review of 1025 cases. J Oral Maxillofac Surg 1992;50(8):778-90.

7) Ungari C, Filiaci F, Riccardi E, Rinna C, Iannetti G. Etiology and incidence of zygomatic fracture: a retrospective study related to a series of 642 patients. Eur Rev Med Pharmacol Sci 2012;16(11): 1559-62.

8) Hönig JF, Merten HA. Classification system and treatment of zygomatic arch fractures in the clinical setting. J Craniofac Surg 2004;15(6): 986-9.

9) Kim J, Kim S, Chung S, Chung YK. Zygomatic arch fracture: a new classification and treatment algorithm with epidemiologic analysis. J Craniofac Surg 2014;25(4):1389-92.

10) Yamamoto $K$, Murakami K, Sugiura T, Fujimoto M, Inoue $M$, Kawakami M, et al. Clinical analysis of isolated zygomatic arch fractures. J Oral Maxillofac Surg 2007;65(3):457-61.

11) Moon JH, Kwon MS, Park SW, Kim YH, Han CY, Kwon JH, et al. [Retrospective study on 527 patients with maxillofacial trauma: a 5 -year experience]. Korean J Otorhinolaryngol-Head Neck Surg 2004;47(4):362-7.

12) Covington DS, Wainwright DJ, Teichgraeber JF, Parks DH. Changing patterns in the epidemiology and treatment of zygoma fractures: 10-year review. J Trauma 1994;37(2):243-8.

13) Karlan MS, Cassisi NJ. Fractures of the zygoma. a geometric, biomechanical, and surgical analysis. Arch Otolaryngol 1979;105(6): 320-7.
14) Strong EB, Sykes JM. Zygoma complex fractures. Facial Plast Surg 1998;14(1):105-15.

15) Fujii N, Yamashiro M. Classification of malar complex fractures using computed tomography. J Oral Maxillofac Surg 1983;41(9):562-7.

16) Kreutziger KL. Surgical management of complex maxillofacial fractures. Laryngoscope 1982;92(2):192-8.

17) Rowe NL, Williams JL. Fractures of the zygomatic complex and orbit. In: Maxillofacial injuries. 1st ed. New York: Livingstone Churchill; 1985. p.435-510.

18) Gillies HD, Kilner TP, Stone D. Fractures of the malar-zygomatic compound: with a description of a new X-ray position. Br J Surg 1927; 14(56):651-6.

19) Swanson E, Vercler C, Yaremchuk MJ, Gordon CR. Modified gillies approach for zygomatic arch fracture reduction in the setting of bicoronal exposure. J Craniofac Surg 2012;23(3):859-62.

20) Carter TG, Bagheri S, Dierks EJ. Towel clip reduction of the depressed zygomatic arch fracture. J Oral Maxillofac Surg 2005;63(8):1244-6.

21) Kim DK, Kim SK, Lee JH, Park CH. Aqua splint suture technique in isolated zygomatic arch fractures. Eur Arch Otorhinolaryngol 2014;271(4):707-11.

22) Akizuki H, Yoshida H, Michi K. Ultrasonographic evaluation during reduction of zygomatic arch fractures. J Craniomaxillofac Surg 1990; 18(6):263-6.

23) Jang CH, Wang WK, Kim ID, Cho JH, Lee JH, Yoon SW. [Open reduction of zygomatic fracture using frontotemporal incision]. Korean J Otorhinolaryngol-Head Neck Surg 1992;35(4):525-32.

24) Gülicher D, Krimmel M, Reinert S. The role of intraoperative ultrasonography in zygomatic complex fracture repair. Int J Oral Maxillofac Surg 2006;35(3):224-30.

25) Pedemonte C, Sáez F, Vargas I, González E, Canales M, Lazo D, et al. $\mathrm{C}$-arm as intraoperative control in reduction of isolated zygomatic arch fractures: a randomized clinical trial. Oral Maxillofac Surg 2016;20(1):79-83

26) Li Z, Yang RT, Li ZB. Applications of computer-assisted navigation for the minimally invasive reduction of isolated zygomatic arch fractures. J Oral Maxillofac Surg 2015;73(9):1778-89.

27) de Queiroz SB, de Lima VN, Bazani PL, Bonardi JP, Magro-Filho O. The use of foley catheter for treatment of unstable fracture zygomatic arch. J Craniofac Surg 2016;27(4):1012.

28) Park CH, Hong SJ, Lee JH, Yang SM, Jung KN, Kwon TK, et al. [The stabilizing method of zygomatic arch fracture using aqua splint suture technique]. Korean J Otorhinolaryngol-Head Neck Surg 2007; 50(3):220-4. 